\title{
Diferenças entre ética e moral, conceito e escopo de ética
}

\section{Differences between ethics and morals, concept and scope of ethics}

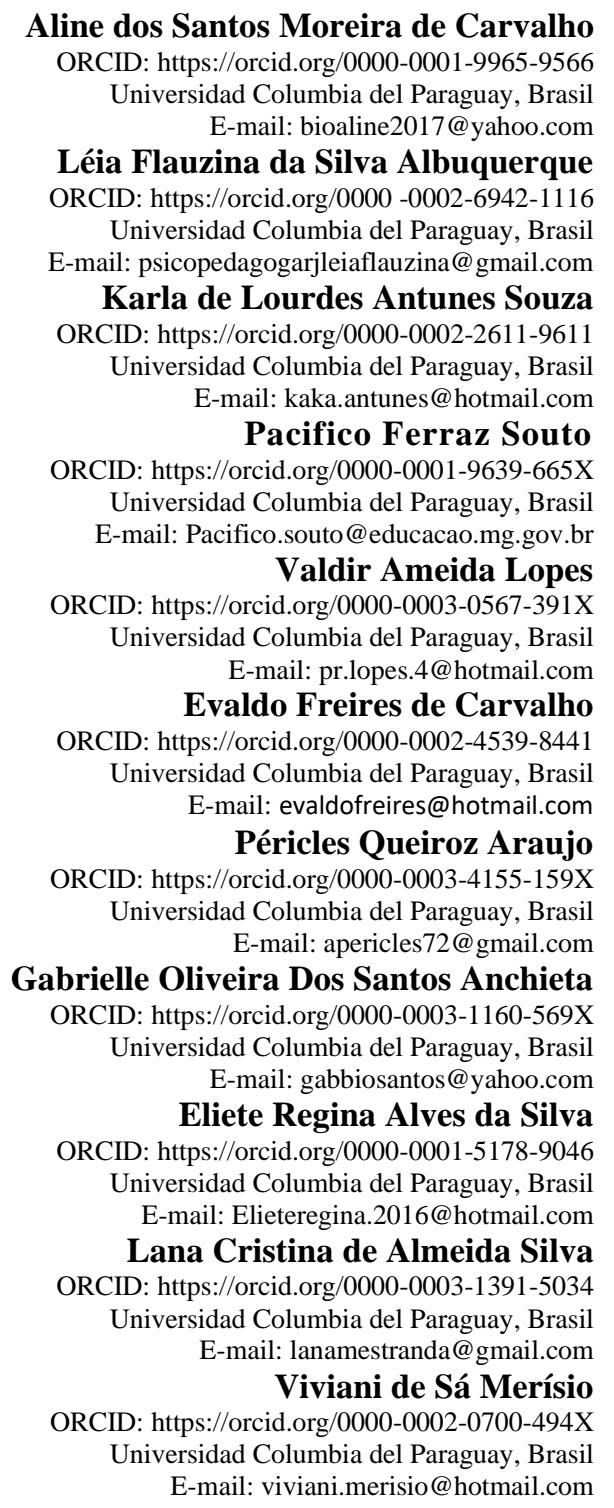

\section{Resumo}

Os conceitos de Ética e também de moral, desde sua gênese e consequente utilização nas ciências e em diferentes áreas de conhecimento, promovem reflexões acerca de conceito, escopo e de diferenças entre ambos, assim como seu significado e presença ou ausência no contexto geral brasileiro. Nesse sentido, o presente artigo objetiva destacar, brevemente, aspectos como conceito e escopo de Ética, sua realidade no contexto brasileiro e as diferenças em relação ao termo moral, utilizando para tal de pesquisa bibliográfica. Os resultados e discussões estão apresentados em três tópicos e as conclusões nas considerações finais.

Palavras-chave: Ética; Moral; Diferenças; Brasil.

\footnotetext{
Abstract

The concepts of Ethics and also of morals, since their genesis and consequent use in the sciences and in different areas of knowledge, promote reflections on the concept, scope and differences between them, as well as their meaning and presence or absence in the general Brazilian context. In this sense, the present article aims to briefly highlight aspects such as the concept and scope of Ethics, its reality in the Brazilian context and the differences in relation to the term
} 
moral, using for this purpose a bibliographic research. The results and discussions are presented in three topics and the conclusions in the final considerations.

Keywords: Ethics; Moral; Differences; Brazil.

\section{Introdução}

Os termos Ética, desde sua concepção e consequente uso nas ciências, promovem algumas reflexões acerca de conceito, escopo e de diferenças entre esse e o conceito de moral.

As tessituras das relações humanas que apresentam comportamentos bons ou maus, são identificados pelos conceitos de Ética e moral, dentro de uma sociedade. Porém no decorrer do tempo, a utilização dos termos ética e moral não tem sido uniforme, ora apresentados como sinônimos, ora com diferentes significados (Rezende, 2006).

Nessa perspectiva, o presente artigo objetiva destacar, brevemente, aspectos como conceito e escopo de Ética, sua realidade no contexto brasileiro e as diferenças em relação ao termo moral, utilizando para tal de pesquisa bibliográfica, conforme concepção de Gil (2008).

\section{Metodologia}

A metodologia utilizada para a produção deste estudo foi de pesquisa bibliográfica, realizada em meio virtual, com artigos disponíveis assim como anais em sites confiáveis, de conteúdo científico.

A pesquisa bibliográfica, ou de fontes secundárias, abrange toda bibliografia já tornada pública em relação ao tema de estudo, desde publicações avulsas, boletins, jornais, revistas, livros, pesquisas, monografias, teses, material cartográfico etc. [...] Dessa forma, a pesquisa bibliográfica não é mera repetição do que já foi dito ou escrito sobre certo assunto, mas propicia o exame de um tema sob novo enfoque ou abordagem, chegando a conclusões inovadoras (Lakatos, Marconi, 2010, p.166).

Sendo assim, foram selecionados artigos e anais, cadernos e teses resultantes de pesquisa em meio virtual, com os descritores: direito a educação, educação e pandemia.

Artigos que não correlacionavam os três descritores foram excluídos. Após a exclusão, foi feita uma leitura analítica que resultou na fundamentação teórica deste estudo, apresentada em resultados e discussões e subdividida em títulos e as conclusões encontram-se nas considerações finais.

\section{3. Ética, Conceito e Escopo}

Gontijo (2006) argumenta que o termo "ética" deriva do termo "ethike" de origem grega, que é utilizado para designar determinado tipo de saber, o que Aristóteles afirmou como o exercício de virtudes morais, reflexão crítica e metódica, que, para a filosofia antiga, tornou-se uma das três partes estudadas (logike, ethike, physike).

Rezende (2006) afirma que ética é entendida como interioridade do ato, que no dicionário Aurélio significa substantivo feminino derivado do adjetivo ético; aplicada nos estudos de juízo de apreciação com relação à conduta humana no que diz respeito ao bem e mal, relativamente ou em absoluto, em qualquer lugar e tempo, grupo ou pessoa.

De acordo com o professor Lustoza (2013), a Ética pode ser considerada como ciência da conduta humana, perante a si a aos outros, que concebe como virtude a prática do bem; é tida também como a apreciação de normas da conduta humana.

Contudo, existe uma aproximação de significado entre ética e moral que apresenta também algumas diferenças. 


\section{4. Ética e Moral, Diferenças}

Gontijo (2006) afirma que o adjetivo ethike, é originado do substantivo ethos (costume, estilo de vida e ação, que definem a morada do ser humano - o espaço torna-se habitável por meio do ethos do ser humano). No mundo latino, o termo ethos foi traduzido, por Cícero (filósofo), como mós, de onde derivou-se o termo moral, que possui uma história semântica muito parecida com ethos e que denota, coletivamente, modo de ser, e, individualmente, caráter.

Sendo assim, na perspectiva filosófica, Ética passou a designar objeto de estudo de uma disciplina tanto quanto o estudo do objeto, assim como moral, que passou a significar tanto o objeto do estudo, quanto o estudo do objeto (Filosofia Moral). Portanto, para a Filosofia, Ética e moral designam a mesma área de fenômenos e o mesmo domínio reflexivo, apesar de algumas dissonâncias relativas a concepção de alguns autores como: a moralidade e a eticidade em Hegel (moralidade interior e eticidade social e política); ética e moral em Paul Ricoeur (moral - normas deveres e obrigações e ética - virtudes e práticas efetivas concretas); moral como objeto de estudo e ética como estudo do objeto (Gontijo, 2006).

Lustoza (2013) escreve que, historicamente, a ética tornou-se mais importante que a moral, o que desenvolveu algumas questões que precisaram ser organizadas ao longo do tempo.

Para o autor, Aristóteles foi o primeiro a organizar essas questões apreciando que os valores morais, derivados dos costumes, objetivam promover a ordem social; na Idade Média, a Ética Cristã aprecia que a felicidade é um objetivo do ser humano e é conquistada por meio da prática do bem; Maquiavel defendeu uma moral própria relacionada ao Estado (Lustoza, 2013).

\section{5. Ética no Brasil}

O Brasil foi descoberto em 1500 d. C. e foi colônia de exploração de Portugal. De acordo com Lustoza (2013), por ter sido sempre explorado de forma vil e para enriquecimento financeiro por parte de outras nações, existiu pouca ou nenhuma regra social estabelecida, o que hoje torna difícil discutir e debater aspectos de problemas nacionais sem tocar em assuntos éticos. As pessoas buscam as origens da problemática nacional brasileira no aspecto social, na insegurança pública e privada, na corrupção. Nesse contexto, há uma falta de contentamento geral em tomar atitudes corretas frente ao monopólio do poder das elites financeiras, onde a sociedade gira em torno (Lustoza, 2013).

De acordo com a UNESCO (Organização das Nações Unidas para Educação, Ciência e Cultura), há, no Brasil, a necessidade de fortalecimento na área de ética e promoção de princípios, práticas e normas éticas (UNESCO, 2021).

Leonardo Boff (2016) afirma que a falta de ética na nação brasileira deriva do processo de colonização, que impôs ao colonizado a submissão e a necessidade de mentir, esconder e fingir que atualmente ganhou grandes proporções (Boff, 2016).

\section{Considerações Finais}

A Ética e a moral possuem semelhanças, complementaridades e diferenças diante do contexto apresentado.

Cabe ressaltar o contexto brasileiro no aspecto ético, sua presença ou ausência, em determinados aspectos sociais, mas principalmente a gênese dessa problemática nacional que ainda demanda graves consequências atualmente, como a corrupção impregnada na sociedade.

\section{Referências}

Agosto, M. T. (2008). Abs da Cruz. Ética e relações sociais um enfoque filosófico. In jacques, M. G. C., et al. org. Relações sociais e ética Centro Edelstein de Pesquisas Sociais 18- 25. http://books.scielo.org

Boff, L. Causas da escandalosa falta de ética no Brasil. Jornal a Gazeta. Espírito Santo, 1 de agosto de 2016. http://www.ijsn.es.gov.br/ConteudoDigital/20160920_aj04406_etica.pdf. 
Brito, J. M, R. "Os valores e a antropologia: para uma leitura fenomenológica" www.eleutheria.ufm.edu/ArticulosPDF/100621_fondo_os.

Cabanas, (1998), Q. "Pedagogía axiológica: la educación ante los valores". Dykinson,

Cabral, R. 2000 "Temas de ética". Faculdade de Filosofia. Braga: Universidade Católica de Braga

Duméry, H. "Axiologie" http://www.universalis.fr/encyclopedie/axiologie/

Foucault T, M. (1998) "As palavras e as coisas". Edições 70

Frondizi, R. (1972) "Valor, estructura y situación". Dianóia, 18(18), 78-112.

Gonçalo, E. "Os valores como fundamento ético do agir humano". Contexto, 3(3), 111-124.

Gontijo, E. D. Os termos 'Ética' e 'Moral'. Revista Mental, 4(7) http://pepsic.bvsalud.org/scielo.php?script=sci_arttext \&pid=S167944272006000200008>.

Hessen, J. (2001) "Filosofia dos valores". Almedina.

Jesinghaus, C. "Estudios acerca de una axiologia formal y fenomenológica". ffyl.uncu.edu.ar/IMG/pdf/12_vol_01_jesinghaus.pdf

Lavelle, L. "Traité des valeurs". Théorie générale de la valeur. Tome I. PUF

Lustoza, H. K. (2013). A crise ética na sociedade brasileira. Revista jurídica Unicuritiba. 1(30), 271-283. http://revista.unicuritiba.edu.br/index.php/RevJur/article/view/563/435>.

Morente, M. (1987) "Fundamentos de filosofia: ontologia dos valores". http://www.consciencia.org/fundamentosfilosofiamorente22.shtml

Ortega y Gasset, J. "Obras completas". Alianza.

Pontarolo, R. "Atividade axiológica na educação". Ponta Grossa: Universidade Estadual de Ponta Grossa.

Renaud, I. "A noção de dever na ética contemporânea". In: J. Brito (Coord.). Temas fundamentais de ética (pp. 31-44). Universidade Católica Portuguesa.

Rezende, M. B. de. (2006) Ética e moral. Revista Paraense de Medicina, 20(3) http://scielo.iec.gov.br/scielo.php?script=sci_a rttext\&pid=S010159072006000300001>.

Schneeewind, J. "Dictionnaire d'éthique et de philosophie morale" (pp. 651-657). PUF

Silva, C. "Valores e valoração: posições éticas num itinerário educativo". Universidade do Porto

Singer, P. "Sobre a ética: ética prática" (pp. 9-23). Martins Fontes

Tugendhat, E. "Lições sobre ética". Vozes.

Valadier, P. "Você disse: valores? A anarquia dos valores: será o relativismo fatal?" (pp. 15-24). Instituto Piaget

UNESCO (2021), Ética no Brasil. UNESCO - Construir a paz nas mentes dos homens e das mulheres, Brasília. 